\title{
A IMPORTÂNCIA DO FORTALECIMENTO DOS ÓRGÃOS MUNICIPAIS DE PROTEĈ̃̃O E DEFESA CIVIL EM PERNAMBUCO, FRENTE ÀS MUDANÇAS CLIMÁTICAS E A INTENSIFICAÇÃO DOS DESASTRES NA ÚLTIMA DÉCADA
}

\author{
Ivânio Darmiton Coutinho de Mendonça ${ }^{1}$
}

\section{RESUMO}

Conhecer a realidade das mudanças climáticas no Brasil e, especialmente, em Pernambuco, nos últimos dez anos, a fim de preparar a população para uma cultura de prevenção, propiciando comunidades resilientes apoiadas por órgãos de Proteção e Defesa Civil e demais atores envolvidos, é o principal objetivo deste artigo. Destarte, faz-se necessário considerar uma mudança de cultura, tanto na forma do governo lidar com os assuntos relacionados à questão do risco e dos desastres, como também na maneira com que as próprias pessoas enxergam esse tema, a fim de minimizar os obstáculos enfrentados na atenuação dos eventos adversos. Infelizmente, nessa linha de raciocínio, ainda estar-se aquém quando se fala em adaptação das cidades. De certo, trata-se de um fenômeno verdadeiramente global e que exercerá um papel fundamental quanto a diversos fatores ligados ao futuro da sociedade. A partir dessa compreensão, a construção de uma nova realidade requer a ampliação da capacidade de percepção dos riscos existentes, da preparação para possíveis catástrofes e transformação do ambiente, para torná-lo menos vulnerável. Além disso, propõe-se a transversalidade do assunto Proteção e Defesa Civil entre os diversos órgãos da administração municipal, sendo fortalecido pelas instituições estaduais e federais.

Palavras-chave: Mudanças Climáticas. Desastres. Proteção e Defesa Civil. Adaptação das Comunidades.

\footnotetext{
${ }^{1}$ Major do Corpo de Bombeiros Militar de Pernambuco. Especialista em Defesa Civil pela Faculdade AVM. Gerente de Assistência Humanitária da Coordenadoria de Defesa Civil do Estado de Pernambuco. Email: ivaniocoutinho@gmail.com
} 


\title{
THE IMPORTANCE OF ORGANIZATIONAL STRENGTHENING MUNICIPALITIES OF CIVIL PROTECTION AND DEFENSE IN PERNAMBUCO, GAINST CLIMATE CHANGE AND INTENSIFICATION OF DISASTERS IN THE LAST DECADE
}

\begin{abstract}
Knowing the reality of climate change in Brazil and especially in Pernambuco, in the last ten years in order to prepare the population for a culture of prevention, providing resilient communities supported by protection agencies and Civil Defense and other stakeholders, is the main objective of this article. Thus, it is necessary to consider a change of culture, both in the form of government to deal with matters relating to the issue of risk and disasters, but also in the way that the very people see this theme in order to minimize the obstacles in mitigating the adverse events. Unfortunately, this line of reasoning, we are still falling short when it comes to adapting the cities. Of course, it is a truly global phenomenon and that will play a key role as the many factors related to the future of society. From this understanding, the construction of a new reality requires the expansion of the capacity of perception of the risks, preparing for possible disasters and transformation of the environment, to make it less vulnerable. In addition, it is proposed the mainstreaming of the issue Protection and Civil Defense of the various bodies of the municipal administration, and strengthened by state and federal institutions.
\end{abstract}

Keywords: Climate Change. Disaster. Protection and Civil Defense. Adaptation of the Communities.

Artigo recebido em 02/05/16 e Aceito em 06/12/16. 


\section{INTRODUÇÃO}

Pode-se noticiar que na evolução da humanidade, durante todo o período de luta pela sobrevivência, o ser humano sempre procurou defender-se do ambiente hostil e das ameaças que o cercavam, minimizando das nefastas consequências dos acidentes, naturais ou não, visando à proteção da sociedade. (NOBRE, J. A. COELHO, L. C. A., 2011, p.02)

Indubitavelmente, nos últimos anos, a ocorrência de fenômenos meteorológicos extremos, em várias partes do mundo, intensifica-se de maneira considerável, demonstrando que há algo incomum ocorrendo na natureza. Não obstante, caracteriza-se pelo aumento dos fatores de risco decorrentes de questões sociais, econômicas e ambientais causadas pela expansão urbana desordenada, degradação ambiental, elevada densidade demográfica, infraestrutura urbana mal planejada e escasso nível de preparação da população. E ainda, o aumento da concentração de gases do efeito estufa e aerossóis na atmosfera favorecendo o aumento na temperatura do planeta. As vulnerabilidades são inúmeras, sendo o aquecimento na temperatura do ambiente um dos fatores que mais influenciou na incidência de desastres naturais. (MARENGO, J. A., 2009, p.05),

No Brasil, desde 2008, os desastres têm sido um grave problema recorrente em diferentes regiões, tendo havido crescimento na capacidade destrutiva de alguns deles, constituindo-se um tema cada vez mais frequente na mídia e entre estudiosos, corroborando com a preocupação e o cuidado de se preparar as pessoas para o enfrentamento de situações que ameaçam a vida humana, pois, habitalmente, a comunidade tem esperado providências exclusivamente do poder público, colocando-se a margem do contexto.

Outrossim, faz-se importante destacar o trabalho dos Órgãos de Proteção e Defesa Civil que privilegia as ações preventivas, em que 0 planejamento se torna uma poderosa ferramenta para a construção e 
consolidação de uma política voltada para a redução dos desastres e seus efeitos. Desse modo, torna-se imperativo ao poder executivo municipal incentivar a criação e implantação de Coordenadorias Municipais de Proteção e Defesa Civil (COMPDEC's), estimulando a participação popular, promovendo ações integrais e sistêmicas, evitando primordialmente a perda de vidas humanas e materiais. (NETO, M.C., 2007, p.03)

\section{METODOLOGIA}

A metodologia a ser utilizada será, basicamente, a pesquisa bibliográfica, documental, exploratória e telematizada, de corte transversal, preconizada por Lakattos (2011), em sua análise da metodologia e pesquisa.

\section{MUDANÇAS CLIMÁTICAS E A INTENSIFICAÇÃO DOS DESASTRES NATURAIS NO BRASIL NA ÚLTIMA DÉCADA}

Atualmente $\mathrm{o}$ mundo tem vivenciado fenômenos com forte poder avassalador, não existindo lugares que estejam livres deles, provocando prejuízos incalculáveis, tanto às pessoas, como ao patrimônio e ao meio ambiente. Assim sendo, a organização humanitária britânica Oxfam, divulgou no final de maio de 2011, que o número de desastres naturais registrados em 140 países pesquisados quase triplicou nos últimos 30 anos. (BBC, www, 2016)

Há que se destacar o fato, de um país com dimensões continentais como o Brasil, fenômenos climáticos extremos ocorram de muitas formas, como enchentes, secas prolongadas, deslizamentos, chuvas de granizos, incêndios florestais, ondas de calor, dentre outros de menor magnitude. Vale dizer, então, que entre os anos de 1991 a 2012, segundo levantamento do Atlas Brasileiro de Desastres Naturais, cerca de 96,2 milhões de pessoas foram 
acometidas. E, ainda, estima-se que, nos próximos anos, as tragédias devam ser intensificadas e os fenômenos antes praticamente desconhecidos pela nação brasileira, se somem as ocorrências já vivenciadas. (O GLOBO, www, 2016)

O país apresentou crescimento em todos os tipos de desastres naturais. De $1^{\circ}$ - de janeiro a 16 de junho de 2010, com registro de 1.635 reconhecimentos de Situação de Emergência ou Estado de Calamidade Pública, superior ao contabilizado em todo ano de 2009, 1.389 ocorrências. (REVISTA EMERGÊNCIA, www, 2016)

$\mathrm{Na}$ prática, as ameaças naturais afetam proporcionalmente mais as populações pobres, em função de que elas, em sua maioria, vivem em zonas de maior densidade populacional, em residências mal construídas e em terrenos mais expostos ao risco. Entretanto, mesmo os grupos mais favorecidos economicamente serão afetados por esse conjunto de riscos, decorrentes de mudanças climáticas. (OLIVEIRA et al., 2010, p. 58)

Com mais de $90 \%$ de probabilidade, a hipótese de que o aquecimento da Terra é fruto da ação humana, foi confirmada, pelo relatório do Intergovernmental Panel on Climate Change (IPCC), sendo causado por intervenções radicais nos ecossistemas e em sua dinâmica, pela expansão demográfica, pela diminuição dos recursos naturais e por graves crises socioeconômicas. Por isso, a questão climática é de difícil solução, já que envolvem complexas relações de interesses econômicos, políticos, sociais e jurídicos. (WALTER, M.K.C., 2007, p.171)

É certo que não sabemos qual será a intensidade dos fenômenos extremos, mas temos convicção de que as mudanças climáticas exercerão um papel fundamental em diversos fatores ligados ao futuro da sociedade, como a segurança hídrica, energética e alimentar. Se não agirmos agora para reduzir o risco de efeitos mais severos das mudanças climáticas, 720 milhões de pessoas podem ficar em situação de pobreza extrema. A conclusão é de um 
dos relatórios do Overseas Development Institute (ODI), que afirma que erradicar a miséria é possível, mas depende de ações efetivas contra o aquecimento do planeta. (OBSERVATÓRIO DO CLIMA, www, 2016)

\section{O IMPACTO SOCIAL DECORRENTE DAS MUDANÇAS CLIMÁTICAS}

A preocupação com as alterações do clima e seus impactos na vida humana e no ambiente é assunto da política internacional há algum tempo. $\mathrm{O}$ mundo está mais atento ou, pelo menos, ciente de que a condição das mudanças climáticas não é um fenômeno qualquer e de que, por sua seriedade, além dos esforços internos de um estado, requer uma participação efetiva da população. (CARVALHO et al., 2012, p. 84).

Não se nega, contudo, a importância de atentar para a ideia da concepção social do desastre. Isto é, a atuação humana ou sua falta tem grande participação na ocorrência e no agravamento de tragédias. "...as pessoas, sociedades e ecossistemas por todo o mundo são vulneráveis em escalas diferentes. As mudanças climáticas interagem com outras ameaças e aumentam seus riscos", disse Chris Fields, co-presidente do Grupo de Trabalho II do IPCC. (INSTITUTO HUMANITAS UNISINOS, www, 2015)

Todo esse contexto é muito complexo, e para o futuro próximo projetamse muitas incertezas para as populações urbanas, já que as vulnerabilidades das comunidades são muitas e não possuem o mesmo caráter "natural" do evento adverso, uma vez que está arraigada nos processos e modos de vida criados pela humanidade.

A ocorrência dos desastres naturais está ligada não somente à susceptibilidade dos mesmos, devido às características geoambientais, mas também à vulnerabilidade do sistema social sob impacto, isto é, o sistema econômico-social-politico-cultural. Normalmente os países em desenvolvimento não possuem boa infraestrutura. $\mathrm{O}$ aumento da pressão populacional e o desenvolvimento econômico forçam cada vez mais a população, em especial a de 
baixa renda, a mudar para as áreas de risco. (ALCÁNTARA-AYALA, 2002, apud, KOBIYAMA, M. et al. 2006, p. 02).

Os municípios brasileiros não estão preparados, prevenidos ou adaptados para os impactos dos desarranjos do clima ou da sua variabilidade. A grande maioria, $93,5 \%$ no total, 5.201 , ainda não elaborou seus registros históricos de eventos extremos e cartas geotécnicas, informações fundamentais para que uma cidade possa ter suas áreas de risco monitoradas. No cenário nacional, a região Nordeste é tida como a mais vulnerável devido aos seus problemas socioeconômicos e ambientais típicos do Semi-Árido. (JARDIM, A.P.M., 2012, p.04).

Durante muito tempo, o trabalho de enfrentamento aos desastres, por parte da Defesa Civil brasileira, concentrou-se nas ações desenvolvidas após o impacto do evento adverso, envolvendo o socorro, a assistência às pessoas atingidas e a reabilitação do cenário do desastre. É por isso que muita gente, ainda hoje, associa as ações de Defesa Civil à coleta, organização e distribuição de donativos, ao repasse de recursos públicos para áreas atingidas por desastres naturais ou a coordenação de serviços assistencialista e de Segurança Pública.

Decerto, é imprescindível a inserção da cultura de prevenção nos municípios, pois, embora não seja possível mensurar os danos e prejuízos que foram evitados com ações preventivas, sabe-se que custear essas ações é social, ambiental e economicamente bem mais vantajosa do que as condutas de resposta e recuperação pós-evento. Ações preventivas consistentes dependem do trabalho executado junto a comunidade, pontual, dentro do contexto específico da realidade vivida. Com este conhecimento, a comunidade terá sucesso no enfrentamento ao fenômeno dos desastres através do investimento na sua capacidade de resiliência, afirmou a Coordenadoria de Defesa Civil do Estado do Paraná. (2008, p.10)

[...] resiliência é a capacidade de um sistema ou comunidade resistir ou mudar de forma para manter um nível aceitável de funcionamento 
e estrutura. Isto é determinado pela capacidade do sistema social de se organizar e aprender com os desastres anteriores, protegendo-se ao minimizar os riscos. (Curso de Gestão Integrada em Defesa Civil CGIDC, 2010, apud, JARDIM, A.P.M., 2012, p.26)

\section{A RELEVÂNCIA DO TRABALHO DE PROTEÇÃO E DEFESA CIVIL NOS MUNICÍPIOS BRASILEIROS}

A preocupação com as alterações climáticas e seus impactos na vida humana e no ambiente é assunto de política internacional há algum tempo.

A Defesa Civil no Brasil fundamenta-se em sistemas abertos com a participação ativa dos governos locais e da comunidade, no desencadeamento das ações preventivas e de resposta aos desastres, e por isso necessita dispor de uma eficiente estrutura próxima à população. Logo, a estrutura básica do trabalho de Proteção e Defesa Civil deve estar localizada no município, cuja comunidade é a primeira a ser atingida por um evento adverso e a ajuda externa normalmente chega tardiamente. Portanto, é importante que a população e o Governo Municipal estejam conscientes da necessidade de um órgão que vise à segurança da coletividade.

A Defesa Civil é o conjunto de ações preventivas, de socorro, assistenciais, reabilitadoras e reconstrutivas destinadas a evitar ou minimizar desastres, a preservar o moral da população e restabelecer a normalidade social, sendo uma das ações a Redução de Desastres. (POLÍTICA NACIONAL DE DEFESA CIVIL, 1995).

Nesse sentido, surge o papel da COMPDEC, que é o Órgão Municipal destinado a coordenar as ações preventivas, preparação de respostas, socorro e recuperação das comunidades e áreas atingidas por desastres, no âmbito do território do município. Isto significa, tornar o município perfeitamente capacitado a agir no momento oportuno, através do acionamento de planos operacionais específicos, previamente elaborados, contando com todos os recursos institucionais, humanos e materiais disponíveis, cadastrados e com 
funções definidas. De acordo com a Organização das Nações Unidas (ONU), "cada dólar investido em prevenção poupa sete dólares gastos em recuperação". (BRASIL, 2009, p.6)

Ademais, a Política Nacional de Proteção e Defesa Civil (PNPDC) é constituída, também, pelas atividades de ações articuladas, conforme disposto na Lei n. ${ }^{\circ}$ 12.608/2012, "deve integrar-se às políticas de ordenamento territorial, desenvolvimento urbano, saúde, meio ambiente, mudanças climáticas, gestão de recursos hídricos, geologia, infraestrutura, educação, ciência e tecnologia e às demais políticas setoriais, tendo em vista a promoção do desenvolvimento sustentável".

Por fim, destaca-se que uma comunidade consciente dos riscos que sofre diante de um desastre natural, está mais bem preparada tanto para evitar ou minimizar a ocorrência de seus impactos, bem como para agir diante dessas catástrofes e, em sua maioria, inevitáveis. Ou seja, a resposta da comunidade determinará o grau de impacto causado pelo desastre natural.

\section{ADAPTAÇÃO DAS COMUNIDADES AOS EVENTOS NATURAIS COM A PARTICIPAÇÃO DOS NUPDEC'S}

Ano após ano torna-se mais evidente que o Mundo está sendo acometido por situações adversas que ocasionam desastres e trazem consigo fortes efeitos. Danos e prejuízos intensificam-se à medida que o homem interfere no processo natural do ecossistema e indicam perigo iminente aos grupos sociais descobertos dos seus direitos e que não dispõem de condições materiais para a autoproteção. (QUEIROZ, J.H.C. de; CARVALHO, N.P.; 2010. p.05).

De fato, os fenômenos que causam os desastres ocorrem eventualmente, mas as atividades de prevenção aos desastres naturais devem ocorrer sequencialmente aos contratempos: antes, durante e depois de sua ocorrência. Assim sendo, evitar que fenômenos naturais severos ocorram foge 
Revista Científica do Corpo de Bombeiros Militar de Pernambuco

Seção 1 - Artigos Técnico Científicos

Artigo publicado no Vol.03 №06 - Edição de JAN a JUN 2017 - ISSN 2359-4829

Versão on-line disponível em: http://www.revistaflammae.com

da capacidade humana. Entretanto, através da prevenção, pode-se desenvolver medidas que minimizem os impactos causados pelos mesmos. (IPEA, www, 2014)

Faz-se importante frisar que, o protagonismo social é fundamental para implementar a seguridade e a proteção civil como estratégia essencial ao desenvolvimento sustentável da humanidade. Isto é, a promoção da participação social nas atividades de Proteção e Defesa Civil é a forma mais efetiva de desenvolver a percepção de riscos nas comunidades e de preparálas para o enfrentamento dos desastres.

Certamente, é através dos Núcleos Comunitários de Proteção e Defesa Civil (NUPDEC) que a COMPDEC pode estabelecer um elo formal com a comunidade, promovendo uma bem-sucedida, gestão participativa e um satisfatório gerenciamento de riscos de desastres. (JARDIM, A.P.M.; 2012. p.07)

Os NUDEC's são os Núcleos Comunitários de Defesa Civil, cuja finalidade é desenvolver um processo de orientação permanente junto à população, têm como principal objetivo a prevenção e minimização dos riscos e desastres nas áreas de maior vulnerabilidade nos municípios. (LUCENA, 2005)

No Brasil, conforme consta no Art. 14 do Decreto n. .5 .376 , de 17 de fevereiro de 2005, os NUPDEC's compreende moradores locais, organizados em um ou mais distritos, bairros, ruas, edifícios, entre outros, cuja finalidade, através da mobilização e participação comunitária, é desenvolver um processo de aprendizado e orientação permanente da comunidade, tendo como principal objetivo à prevenção e minimização dos riscos e desastres, contribuindo para uma mudança cultural e comportamental dos cidadãos, tendo como consequência, uma melhora na segurança global da população. Os componentes são cidadãos voluntários organizados, caracterizando-se por uma relação entre a população local e o Sistema Nacional de Proteção e Defesa Civil (SINPDEC). 
Revista Científica do Corpo de Bombeiros Militar de Pernambuco

Seção 1 - Artigos Técnico Científicos

Artigo publicado no Vol.03 №06 - Edição de JAN a JUN 2017 - ISSN 2359-4829

Versão on-line disponível em: http://www.revistaflammae.com

Deve-se apontar que, é a noção de corresponsabilidade que deve ser repassada a todos os segmentos sociais, como agentes diretos do risco. É ao mesmo tempo a culpa e a solução, pois ao perceber-se como responsável pelo risco, é possível visualizar-se, também, como agente passível de reação, aquele que está no controle e, portanto tem a capacidade de modificar a produção daquilo que the coloca em risco.

Esclarece-se, portanto, que o grande diferencial é a íntima relação que os gestores das COMPDEC's têm com a população de área de risco, através dos voluntários dos NUPDEC's e das ferramentas como o diagnóstico situacional. Segundo relatou Pereira: "Desta forma a gestão de risco no município vem se consolidando como uma importante política pública, seja na proteção de milhares de pessoas ou na preservação de vidas. (Revista Vértice, Conselho Regional de Engenharia e Arquitetura /Minas Gerais: 2011. p.13).

\section{EXPERIÊNCIAS EXITOSAS DAS AÇÕES DE PROTEÇÃO E DEFESA CIVIL NO ESTADO DE PERNAMBUCO}

Recomenda-se que todo município possua um Órgão de Proteção e Defesa Civil legalmente instituído e estruturado, evitando a possibilidade de apresentarem comunidades vulneráveis, pela falta de conhecimento sobre os riscos a que estão expostas, bem como, estarem desprovidas de ações de prevenção, mitigação e preparação.

Além disso, é preciso que o município invista preventivamente na instalação de sistemas de monitoramento, alerta e alarme, pois constituem importantes ferramentas que podem salvar vidas e reduzir consideravelmente danos materiais decorrentes de desastres, facilitando a mobilização das equipes técnicas de Proteção e Defesa Civil, de outros órgãos e de pessoas estejam em áreas de risco, em tempo hábil. 
Nessa trajetória, é importantíssimo instituir os NUPDEC's, a fim de se estabelecer uma relação formal com os moradores, promovendo uma gestão participativa através da construção de redes com envolvimento de organizações sociais. Por outro lado, isto significa tornar o município perfeitamente capacitado a agir no momento oportuno, através do acionamento de planos operacionais específicos, previamente elaborados, contando com todos os recursos institucionais, humanos e materiais disponíveis, cadastrados e com funções definidas. Conforme asseverou Souza (1994): "Tudo o que acontece no mundo, seja no meu país, na minha cidade ou no meu bairro, acontece comigo. Então eu preciso participar das decisões que interferem na minha vida".

Nesse sentido, projetos têm sido surpreendentemente aprovados pela sociedade e pelas instituições governamentais, sendo apoiados continuamente. O desafio, portanto, é a gestão participativa. (MINISTÉRIO DA INTEGRAÇÃO, www, 2015)

Como signatário dos Marcos de Ação de Hyogo (MAH) e Sendai (MAS), o Brasil realizou uma série de ações para reduzir os riscos de desastres nas cidades e nas comunidades, através de atividades de Proteção e Defesa Civil, em alguns municípios; a exemplo o Modelo de Gestão de Risco da cidade do Recife/PE, implementado por meio do Programa Guarda-Chuva, que, nos últimos anos, diminuiu em 7 mil o número de pontos de risco da cidade. É por meio deste programa que a Prefeitura desenvolve, durante todo o ano, ações de caráter preventivo e permanente de monitoramento nas áreas de morro e alagados da capital pernambucana. Com a chegada do período chuvoso na cidade, este trabalho é intensificado através da Operação Inverno. Entre as atividades, estão vistorias técnicas nos imóveis que se encontram nas áreas de risco da cidade, orientação dos moradores sobre práticas seguras e procedimentos em situações de emergência, ações informativas com a distribuição de folders e cartilhas aos moradores, assim como a colocação de 
Ionas plásticas nas encostas, que são repostas continuamente. Com essa atuação nos 3.400 pontos de risco do Recife, a Defesa Civil tem alcançados números expressivos ao longo dos últimos anos, inclusive, não tendo registrado nenhuma morte ou grave acidente no ano de 2012. (PREFEITURA DO RECIFE, www, 2015)

Outro exemplo, ainda no município de Recife/PE, outra atividade tecnológica é o monitoramento dos morros, através de sensores utilizados para antecipar o alerta de deslizamento de morros, numa com o Centro Nacional de Monitoramento e Alertas de Desastres Naturais (CEMADEN), os quais totalizam 100 (cem) primas (espelhos refletores) colocados em casas e em estacas nos quintais da comunidade e uma estação robotizada de leitura dos prismas alocada em uma caixa d’água da Escola Estadual Lagoa Encantada, cuja função é detectar deslocamentos de terra e, com isso permitir antecipadamente a emissão sinais de alerta de deslizamentos de encosta para os moradores com até duas horas de antecedência, com base em deslocamentos de terra na faixa de um milímetro, estes aparelhos enviarão informações em tempo real para o CEMADEN que propagará a informação para as Coordenadorias Estadual e Municipal de Proteção e Defesa Civil. (FOLHA DE PERNAMBUCO, www, 2016)

Corroborando com o exposto, outra ação de bastante referência em Pernambuco é o projeto Pluviômetro nas Comunidades, caracteriza-se pela distribuição e instalação de aparelhos semiautomáticos que medem a quantidade de chuvas, instalados em áreas de risco vulneráveis a escorregamento de massa e alagamentos, que conta a operatividade dos próprios moradores, cuja mobilização comunitária para a redução de risco conta com a participação de líderes comunitários e dos jovens que participam do NUPDEC local. (CEMADEN, www, 2015)

Outrossim, é importante enfatizar na esfera Municipal recifense o Programa Parceria nos Morros, cuja intervenção em áreas de risco objetiva 
reduzir situações críticas e garantir mais segurança para os moradores durante o inverno envolvendo obras de pequeno porte executadas com a mão de obra de representantes da própria comunidade, mediante o acompanhamento técnico e a disponibilização de material de construção, bem como, o cadastramento do número do celular de moradores de áreas de risco, através do site da prefeitura para o recebimento do alerta de chuva via SMS, a fim de avisar a população das previsões de chuvas fortes que forem emitidas pela Agência Pernambucana de Águas e Climas (APAC). (INNOVACION LOCAL, www, 2015)

Faz-se importante frisar, a experiência vivenciada pelo município de Jaboatão dos Guararapes/PE, em que se trabalham as ações preventivas de Defesa Civil através dos jovens e que o resultado disso é a melhoria da qualidade de vida da comunidade e a redução dos índices de exclusão social de jovens e adolescentes, tendo sido o único município do país a realizar uma Conferência Municipal de Defesa Civil Juvenil. A Conferência Juvenil reuniu jovens de diversas escolas e de diferentes bairros para discutir "Defesa Civil", tendo como foco os temas estabelecidos pelo Decreto Presidencial de 27 de Outubro de 2009. (PREFEITURA DE JABOATÃO DOS GUARARAPES, www, 2015)

Por fim, cabe-se ressaltar que iniciativas como essas, em todo o Brasil, são imprescindíveis para a formulação de projetos que visem alavancar recursos externos para investimentos em Proteção e Defesa Civil, e consequentemente na redução do risco de desastres.

\section{O CAMINHO A SER PERCORRIDO PARA O FORTALECIMENTO DA ESTRUTURA DAS COMPDEC'S}

De suma importância é o tema ora estudado, ressaltando a necessidade da população de se organizar, se preparar e se orientar quanto ao que fazer e 
como fazer no tocante à prevenção e resposta aos desastres, cabendo ao poder executivo municipal incentivar a criação e implantação de COMPDEC's ou órgão similar. (BRASIL, 2009, p.3)

O país, a sociedade e as comunidades precisam estar mais instrumentalizadas para lidar com o potencial destrutivo dos fenômenos extremos, cada vez mais prováveis no futuro. Assim, nunca foi tão clara a necessidade de a sociedade se organizar para assumir a proteção dos cidadãos. (CEPED, www, 2015)

Entretanto, fazendo referência ao discurso da prevenção e minimização dos efeitos catastróficos, é importante manter o foco nas ações de gestão de risco e desastre diante da possibilidade de ocorrência de novas catástrofes. Isto é, atenção à possibilidade ou à iminência de desastres que caracteriza as contribuições da área da Defesa Civil para o desenvolvimento social e a distingue da das demais áreas do serviço público. (PREFEITURA DE RECIFE, www, 2015)

A COMPDEC, portanto, tem sua importância fundamentada no fato de que, sem a sua criação, os Sistemas Nacional, Estadual e Municipal não poderão cumprir suas incumbências previstas na legislação, pois, os dois primeiros sistemas só existirão em sua plenitude, se houver Sistema Municipal de Proteção e Defesa Civil que cumpra as suas competências. (JUNIOR, D.P.; BARROS, A.B. de; 2010, p.02)

Todas essas mudanças objetivam melhorar o modelo até então em uso no país, quanto ao gerenciamento das ações de Defesa Civil, transformando a cultura da reatividade em proatividade; esta é caracterizada pelo agir no período de normalidade, antecipando-se aos possíveis desastres, utilizando-se dos meios disponíveis para se trabalhar a prevenção às calamidades, enquanto aquela: a cultura da reatividade é caracterizada pela inércia ou insipiência no período de calmaria, agindo apenas quando da anormalidade, colocando-se 
em uma postura receptora, limitando-se a atuar apenas no momento em que 0 desastre ocorre. (DEFESA CIVIL DO CEARÁ, www, 2015)

Neste contexto, o Ministério da Integração Nacional e a Secretaria Nacional de Defesa Civil (SEDEC) publicou a Apostila sobre Implantação e Operacionalização de uma COMDEC (2009), hoje denominada COMPDEC, que objetiva conscientizar os governos municipais e a comunidade sobre a importância da criação, da implantação e da operacionalização das Coordenadorias de Proteção e Defesa Civil nos municípios brasileiros. (BRASIL, 2009, p.4)

Decerto, o fortalecimento do tecido social e o estabelecimento de redes de Proteção e Defesa Civil são as opções mais importantes e eficazes como mecanismos de autoproteção e prevenção de desastres. Um sistema efetivo de prevenção e resposta a desastres, com participação decisiva de estados e municípios, minimizará o custo humano de tais ocorrências e reafirmará a coesão nacional pela solidariedade. (DEFESA CIVIL DO CEARÁ, www, 2015)

\section{CONSIDERAÇÕES FINAIS}

A atenuação dos efeitos das mudanças climáticas globais e a adaptação a estas são os maiores desafios da humanidade neste início de século, haja vista a carência de ações governamentais voltadas para esta temática. Logo, cabe-nos utilizar de instrumentos norteadores das ações, para que possamos mitigar seus efeitos quer seja através do aumento da resiliência das populações mais suscetíveis, ou através da criação e fortalecimento dos organismos de Proteção e Defesa Civil nos municípios brasileiros.

No cenário nacional, a região Nordeste, na qual encontra-se inserida o Estado de Pernambuco, é tida como a mais vulnerável do país, e necessita de atenção especial. Dentre as razões para tal condição, estão os seus problemas 
Revista Científica do Corpo de Bombeiros Militar de Pernambuco

Seção 1 - Artigos Técnico Científicos

Artigo publicado no Vol.03 №06 - Edição de JAN a JUN 2017 - ISSN 2359-4829

Versão on-line disponível em: http://www.revistaflammae.com

socioeconômicos e ambientais, escassez de água, agricultura precária e alta concentração de pessoas na região, típicos do Semi-Árido.

A Proteção Civil é a ação e direito de todos, ou seja, é a atividade que deve ser desenvolvida por pessoas, entidades (públicas e privadas), autarquias locais, e pelo Estado. Infelizmente, ainda há uma sensível ausência da abordagem concretamente prevencionista considerando os fatores vinculados ao cuidado de preparar as pessoas para o enfrentamento de situações as quais possam fugir ao controle e assim constituir uma ameaça à vida humana; isso demonstra, uma cultura totalmente voltada para a reatividade, cujo futuro requer que muito mais seja feito pelos formuladores de políticas para melhor compreender e gerenciar com mais eficácia os riscos existentes e vindouros.

Quando se trata de desastres, o tema Proteção e Defesa Civil, comunidades e voluntariado, caminham para um mesmo lado, o da organização das NUPDEC's. É esta organização que vai definir a vulnerabilidade das comunidades frente a uma hipótese de uma catástrofe, e, vai determinar o tamanho da resposta, os danos causados e os consequentes prejuízos, e por isso necessita dispor de uma eficiente estrutura próxima à população.

Partindo do pressuposto de que a ocorrência de um desastre é uma possibilidade sempre real, uma sociedade bem informada resultará numa sociedade protegida. A intenção principal não é ser alarmista, e sim informar, esclarecer a realidade e, principalmente, mostrar que algo tem que ser feito.

Para tanto, destaca-se a importância de compartilhar experiências de enfrentamento às situações de risco, com ações voltadas à prevenção e, também, envolver mais a população nas ações de Proteção e Defesa Civil.

Conclui-se que mesmo com a participação das esferas Estadual e Federal em um SINPDEC, são nos municípios que os desastres acontecem, e estes são os responsáveis pela execução da PNPDC em nível local. Nesse 
sentido, é preciso o esforço conjunto no intuito de se fomentar uma sociedade resiliente, consciente de seu papel, partícipe do planejamento e das ações em Proteção e Defesa Civil no enfrentamento aos desastres.

\section{REFERÊNCIAS BIBLIOGRÁFICAS:}

BRASIL, Ministério da Integração Nacional. CASTRO, Antonio Luiz Coimbra de. Política Nacional de Defesa Civil. Brasília: Ministério da Integração Nacional. Secretaria Nacional de Defesa Civil, 2000a.

, Antonio Luiz Coimbra de. Segurança Global da População. Brasília: Ministério da Integração Nacional. Secretaria Nacional de Defesa Civil, 2000b.

ACADEMIA BRASILEIRA DE CIÊNCIAS. Simpósio Mudanças Climáticas e Desastres Naturais no Brasil: Desafios e Oportunidades para o Setor de Seguros.

Disponível em: www.abc.org.br/article.php3?id article=2913\%3E.\%20Acesso\%20em:\%20 28\%20jan.\%202014. Acesso em: 28jan14.

AMAMBAI NOTíCIAS. Agência Brasil. Seminário sobre mudanças climáticas em Recife marca Dia Internacional de Redução de Desastres. Disponível em: www.amambainoticias.com.br/brasil/seminario-sobre-mudancas-climaticasem-recife-marca-dia-internacional-de-reducao-de-desastres. Acesso em: 28jan14.

BBC. BBC International. Número de desastres climáticos triplicou desde 1980, diz ONG britânica. Disponível em: www.bbc.com/portuguese/noticias/2011/05/110523 desastres climaticos mdb.shtml. Acesso em: 27jul16.

BRASIL. CEMADEN. Projeto Pluviômetros nas Comunidades. Disponível em: www.cemaden.gov.br/pluviometros/materialdidatico.php?menu=materialdid atico. Acesso em: 26jan14.

BRASIL. Instituto de Pesquisa Econômica Aplicada. Mudanças Climáticas Sociedade de risco. Disponível em: www.ipea.gov.br/desafios/index.php?option=com content\&view=article\&id $=2600:$ catid=28\&ltemid=23. Acesso em: $28 j a n 14$. 
BRASIL. Instituto de Pesquisa Econômica Aplicada. Texto base da $1^{\underline{a}}$ Conferência de Defesa Civil. Disponível em: www.ipea.gov.br/participacao/images/pdfs/conferencias/Defesa Civil/texto base 1 conferencia defesa civil.doc. Acesso em: 28jan14.

Brasil. Ministério da Integração Nacional. Secretaria Nacional de Defesa Civil. Departamento de Minimização de Desastres. Apostila sobre Implantação e Operacionalização de COMDEC. Brasília: 2009. p.03-06.

. Secretaria Nacional de Defesa Civil. Manual de Desastres Humanos: desastres humanos de natureza tecnológica. Brasília, 2005.

. Secretaria Nacional de Defesa Civil. Política Nacional de Defesa Civil. Brasília, 2008.

Secretaria Nacional de Defesa Civil. Universidade Federal de Santa Catarina. Centro Universitário de Estudos e Pesquisas sobre Desastres. Gestão de riscos e de desastres: contribuições da psicologia. Curso à distância / Centro Universitário de Estudos e Pesquisas sobre Desastres. Florianópolis: CEPED, 2010. p.60.

Ministério da Integração. Disponível em: www.integracao.gov.br/web/guest/defesacivil. Acesso em: 16 out13.

. CASTRO, Antonio Luiz Coimbra de. Política Nacional de Defesa Civil. Brasília: Ministério da Integração Nacional. Secretaria Nacional de Defesa Civil, 2000a.

. CASTRO, Antonio Luiz Coimbra de. Segurança Global da População. Brasília: Ministério da Integração Nacional. Secretaria Nacional de Defesa Civil, 2000b.

Disponível em: www.brasil.gov.br/ciencia-e-tecnologia/2014/05/mudancasclimaticas-reforcam-acoes-de-prevencao-dos-brics. Acesso em: 28jan14.

CALHEIROS, Lélio Bringel, et al. Apostila sobre implantação e operacionalização de COMDEC. Brasília: Ministério da Integração Nacional. Secretaria Nacional de Defesa Civil, 2009.

CARE. Manual Formação de Núcleos Comunitários de Defesa Civil NUDECs. Disponível em: http://www.care.org.br/wp- 
content/uploads/2010/08/MANUAL FormacaoNUDECs CAREBrasil FINAL.pdf . (pág 58). Acesso em: 28jan14.

CARTAGENA, Sarah. Clima e desastres naturais. Revista Com Ciência Ambiental, São Paulo, n. 5, p. 50-59, 2011.

CARVALHO, D.W. de; DAMACENA, F.D.L.; A intensificação dos desastres naturais, as mudanças climáticas e o papel do Direito Ambiental. Brasília: 2012. p.84 -95.

CASTRO, Antonio Luiz Coimbra de. Manual de Planejamento em Defesa Civil. Brasília: Ministério da Integração Nacional. Secretaria Nacional de Defesa Civil, v. I, II, III e IV, 1999.

CBN. Governo Federal reconheceu 3.747 decretos de situação de Emergência em 2013. Disponível em: www.cbn.globoradio.globo.com/editorias/reportercbn/2014/01/28/GOVERNO-FEDERAL-RECEONHECEU-3747-DECRETOSDE-SITUACAO-DE-EMERGENCIA-EM-2013.htm. Acesso em: 28jan14.

CEPED. UFSC. $1^{\text {a }}$ Carta Nacional de Defesa Civil. Disponível em: www.ceped.ufsc.br/wp-content/uploads/2009/01/PR-258-1\%C2\%AA-CartaNacional-de-Defesa-Civil.pdf. Acesso em: 28jan14.

DEFESA CIVIL DE ARARUAMA. Mudanças climáticas e seus impactos nos desastres naturais e nas ações de defesa civil. Disponível em: http://defesacivilararuama.blogspot.com.br/2011/01/interessante-estudosobre-as-mudancas.html, Acesso em: 28jan14.

DEFESA CIVIL DO CEARÁ. Diretrizes aprovadas na 1ํㅡㄹ Conferência Nacional de Defesa Civil. Disponível em: $\underline{w} w w$.defesacivil.ce.gov.br/index.php?option=com phocadownload\&view=C ategory\&id=27:outros\&download=246:p-p-1\&ltemid=15.html, Acesso em: 28jan14.

DEFESA CIVIL DO CEARÁ. Planos de Contingência em Desastres: uma necessidade para o Ceará. Disponível em: www.defesacivil.ce.gov.br/index.php?option=com phocadownload\&view=C ategory\&id=63:\&download=266: \&ltemid=15.html ${ }_{2}$ Acesso em: 27 jan14.

DUARTE, Eric Brum de Lima. Defesa Civil. Brasília, 2013. 
FERNANDO, Paulo. Área de risco é desocupada em Porto Alegre. Revista Com Ciência Ambiental, São Paulo, n. 38, p. 86-89, 2011.

FERNANDO, Paulo. Ciência brasileira aprofunda pesquisa sobre o clima. Revista Com Ciência Ambiental, São Paulo, n. 39, p. 02-10, 2011.

FERNANDO, Paulo. Piauí cria comitê para prevenir Desastres. Revista Com Ciência Ambiental, São Paulo, n. 38, p. 80-85, 2011.

FERNANDO, Paulo. Temos de focar nas ações de prevenção. Revista Com Ciência Ambiental, São Paulo, n. 34, p. 12-15, 2011.

FERREIRA, Chico. Estiagem avança no semiárido. Revista Com Ciência Ambiental, São Paulo, n. 34, p. 60-71, 2011.

FOLHAPE. Morros terão sensores para monitorar deslizamentos. Disponível em: www.folhape.com.br/cotidiano/2016/4/morros-terao-sensores-paramonitorar-deslizamentos-0499.html, Acesso em: 26abr16.

G1.Globo. Brasil em emergência: 1/3 das cidades do país decretou situação de emergência ou estado de calamidade em 2013. Disponível em: g1.globo.com/brasil/pais-emergencia-2013/infografico/platb/, Acesso em: 28jan14.

G1.Globo. Governo reconhece n. recorde de decretos de emergência em 2013. Disponível em: g1.globo.com/brasil/noticia/2014/01/governo-reconhecen-recorde-de-decretos-de-emergencia-em-2013.html, Acesso em: 28jan14.

GRANDELLE, R.; Mudanças climáticas podem ampliar tragédias naturais no Brasil - País planeja mais do que dobrar número de municípios incluídos em rede de monitoramento de catástrofes.

INNOVACIONLOCAL. Parceria nos morros. Disponível em: www.innovacionlocal.org/files/015parceria nos morros.pdf. Acesso em: 16 out13.

IPCC. Contribution of Working Groups I, II and III to the Foruth Assessment Reporto $f$ the Intergovernmental Panel on Climate Change. Core Writing Team, Pachauri, R.K. and Reisinger, A. (Eds.), Geneva, Switzerland. p.104.

JABOATÃO. Conferência juvenil defesa civil reunirá $\mathbf{3 0 0}$ jovens. Disponível em: www.jaboatao.pe.gov.br/jaboatao/prefeitura/prefeitura/2010/01/26/NWS,41 
1494,51,546,JABOATAO,2132-I-CONFERENCIA-JUVENIL-DEFESA-CIVILREUNIRA-300-JOVENS.aspX. Acesso em: 18jan14.

JABOATÃO. Juventude jaboatonense inicia discussões sobre defesa civil. Disponível em: www.jaboatao.pe.gov.br/jaboatao/prefeitura/prefeitura/2010/01/28/NWS,41 1505,51,546,JABOATAO,2132-JUVENTUDE-JABOATONENSE-INICIADISCUSSOES-SOBRE-DEFESA-CIVIL.aspX. Acesso em: 17jan14.

JARDIM, A.P.M.; Defesa Civil no Ceará: incentivo à participação social através do protagonismo Juvenil. Fortaleza: 2012. p.04-26.

JC. Sensores para monitorar morros são instalados no Recife. Disponível em: http://jconline.ne10.uol.com.br/canal/cidades/geral/noticia/2016/04/26/sens ores-para-monitorar-morros-sao-instalados-no-recife-232851.php. Acesso em: 26 abr16.

JUNIOR, D.P.; BARROS, A.B. de; A implantação e a operacionalização de Coordenadorias Municipais de Defesa Civil (COMDEC) nos municípios das regiões norte e noroeste do Estado do Rio de Janeiro: Uma análise crítica. Fortaleza,: 2010. p.2

KOBIYAMA, M. et al.; Prevenção de desastres naturais: conceitos básicos. Florianópolis: 2006. p.02-31.

LUCENA, R. Manual de Orientação: formação de NUDEC's. Jaboatão dos Guararapes: 2005. p.11.

MARENGO, J.A.; Mudanças Climáticas, Condições Meteorológicas Extremas e Eventos Climáticos no Brasil. p.5.

MARGARIDA, Caroline; NASCIMENTO, Cristiane Aparecida do; DALMAU, Marcos B.L.; Prevenção e riscos tecnológicos: experiência com produtos perigosos. Revista Com Ciência Ambiental, São Paulo, n. 34, p.82-88, 2011.

NASCIMENTO, L.C.D. do; COELHO, L.C.A; Planejamento, Gestão e Coordenação das Ações de Resposta aos Desastres Envolvendo Vítimas Humanas, p.2.

NETO, M.C; Aspectos Jurídicos das Atividades de Defesa Civil. Brasília: 2007. p.3.

NOBRE, J. A.; COELHO, L. C. A.; Planejamento, gestão e coordenação das ações de resposta aos desastres envolvendo vítimas humanas. 2011. 
O GLOBO. Mudanças climáticas podem ampliar tragédias naturais no Brasil. Disponível em: http://oglobo.globo.com/sociedade/ciencia/mudancasclimaticas-podem-ampliar-tragedias-naturais-no-brasil10220605\#ixzz3UaHwPbU4. Acesso em: 05nov13.

Países anunciam metas de combate às mudanças climáticas em cúpula da ONU. Disponível em: oglobo.globo.com/sociedade/sustentabilidade/paises-anunciam-metasde-combate-as-mudancas-climaticas-em-cupula-da-onu-14016664. Acesso em: 24out14.

OBSERVATÓRIO DO CLIMA. Crise climática pode levar $\mathbf{7 2 0}$ milhões a miséria. Disponível em: http://www.observatoriodoclima.eco.br/crise-climaticapode-levar-720-milhoes-a-miseria. Acesso em: 27jun16.

OLIVEIRA, Marcos de et al.; Capacitação Básica em Defesa Civil. Florianópolis: 2012.

PAIVA, Edvaldo Araújo de; GOMES, James Joyce Bezerra; NASCIMENTO, Joel Ferreira do; Riscos controlados. Revista Emergência, São Paulo, n. 17, p.31-33, 2009.

Paraná. Casa Militar. Coordenadoria Estadual de Defesa Civil. Defesa Civil para Prefeitos. Manual para implementação e desenvolvimento de Coordenadorias Municipais de Defesa Civil no Estado do Paraná. Paraná: 2008. p.10.

PEREIRA, C.V.L.; Temos de focar nas ações de prevenção. Revista Vértice, Minas Gerais, n. 06, p.13, 2011.

PREVENTION WEB. Texto da 2a Conferência Nacional de Proteção e Defesa Civil. Disponível em: www.preventionweb.net/applications/hfa/lgsat/en/image/href/3430.

Acesso em: 26out14.

QUEIROZ, J.H.C. de; CARVALHO, N.P.; Efeitos Jurídicos do Desastre e o Desastre Jurídico dos Efeitos: Fragilidade normativa na gestão para desastres no Brasil. Fortaleza: 2010. p.5. 
Revista Científica do Corpo de Bombeiros Militar de Pernambuco Seção 1 - Artigos Técnico Científicos

Artigo publicado no Vol.03 №06 - Edição de JAN a JUN 2017 - ISSN 2359-4829

Versão on-line disponível em: http://www.revistaflammae.com

RECIFE. Programa Guarda Chuva. Disponível em: www.recife.pe.gov.br/especiais/guardachuval. Acesso em: 26out14.

RECIFE. Texto-base da 1 a Conferência Municipal de Defesa Civil da Cidade do Recife. Disponível em: www.recife.pe.gov.br/noticias/arquivos/2080.pdf. Acesso em: 29jan14.

REVISTA Logística

em: www.revistaemergencia.com.br/edicoes/11/2012/J9y4.

28jun16.

Revista Vértice, Conselho Regional de Engenharia e Arquitetura (CREA), Minas Gerais: 2011, p.13.

SOUZA, Celina. Políticas públicas: uma revisão da literatura. Sociologias. Porto Alegre, n. 16, 2006.

SOUZA, H.J. de; RODRIGUES, C.; Ética e cidadania. São Paulo: Moderna, 1994.

SOUZA, Pedro Paulo de et al. Ponderações sobre a Defesa Civil no Brasil e seus desdobramentos futuros com base na análise da legislação existente. Revista Com Ciência Ambiental, São Paulo, n. 38, p. 10, p.70-77, 2011.

SOUZA, Thiago. Falta de investimentos amplia cenário de risco. Revista Com Ciência Ambiental, São Paulo, n. 34, p.72-79, 2011.

UNISINOS. IPCC: Novo relatório é alerta para governos e sociedade. Disponível em: http://www.ihu.unisinos.br/noticias/529806-ipcc-novo-relatorio-ealerta-para-governos-e-sociedade, Acesso em: 21jan15.

UNIVALI. As Mudanças Climáticas e a Formação do Direito dos Desastres.

Disponível

em: http://www6.univali.br/seer/index.php/nej/article/view/5130. Acesso em: 28jan14.

UOL. Última Instância. É preciso mudar o clima da política de mudanças climáticas no Brasil. em: http://ultimainstancia.uol.com.br/conteudo/colunas/67635/e+preciso+mud 
Revista Científica do Corpo de Bombeiros Militar de Pernambuco

Seção 1 - Artigos Técnico Científicos

Artigo publicado no Vol.03 №06 - Edição de JAN a JUN 2017 - ISSN 2359-4829

Versão on-line disponível em: http://www.revistaflammae.com

ar+o+clima+da+politica+de+mudancas+climaticas+no+brasil.shtml. Acesso em: 28jan14.

VICTOR, Cilene. O que a ciência pode fazer? Revista Com Ciência Ambiental, São Paulo, n. 34, p. 54-59, 2011.

WALTER, M.K.C.; Mudanças Climáticas: Uma Verdade Inconveniente, Barueri: 2006. p.171. 